Bull. Chem. Soc. Ethiop. 2018, 32(1), 13-25.

ISSN 1011-3924

(C) 2018 Chemical Society of Ethiopia and The Authors

Printed in Ethiopia

DOI: https://dx.doi.org/10.4314/bcse.v32i1.2

\title{
CORRELATION BETWEEN CAFFEINE CONTENTS OF GREEN COFFEE BEANS AND ALTITUDES OF THE COFFEE PLANTS GROWN IN SOUTHWEST ETHIOPIA
}

\author{
Mulu Hagos ${ }^{1}$, Mesfin Redi-Abshiro ${ }^{1 *}$, Bhagwan Singh Chandravanshi ${ }^{1}$, Estifanos Ele ${ }^{1}$, \\ Ahmed M. Mohammed ${ }^{1}$ and Hassen Mamo ${ }^{2}$ \\ ${ }^{1}$ Department of Chemistry, College of Natural Sciences, Addis Ababa University, P.O. Box \\ 1176, Addis Ababa, Ethiopia \\ ${ }^{2}$ Department of Microbial, Cellular and Molecular Biology, College of Natural Sciences, Addis \\ Ababa University, P.O. Box 1176, Addis Ababa, Ethiopia
}

(Received November 15, 2017; Revised March 23, 2018; Accepted March 24, 2018)

\begin{abstract}
Caffeine contents of 45 green coffee bean samples collected from coffee plants grown at different altitudes in Southwest Ethiopia was determined by UV-Vis spectrophotometry. The caffeine contents were found in the range of $0.62-1.2 \%(\mathrm{w} / \mathrm{w})$. A moderate negative correlation $(\mathrm{R}=0.5463)$ was found between the caffeine contents of green coffee beans and the altitudes at which the coffee plants were grown. The caffeine contents of 9 of the green coffee bean samples analyzed by high performance liquid chromatography (HPLC) provided comparable results in the range of $0.60-1.1 \%(w / w)$. Statistical analysis of data (t-test) indicated absence of significant differences between the caffeine contents obtained by the two methods. Nonetheless, HPLC method is precise, accurate and reliable in determining caffeine content in green coffee bean samples while the UV-Vis spectrophotometry is simple, rapid, precise and more economical.
\end{abstract}

KEY WORDS: Green coffee beans, Caffeine, Correlation between caffeine content and altitude of coffee plant, UV-Vis spectrophotometry, High performance liquid chromatography, Ethiopia

\section{INTRODUCTION}

The name coffee is derived from the name of the province Kaffa where shepherds from Abyssinia/Ethiopia discovered the coffee beans in the 6th century $[1,2]$. Since then, coffee has become one of the most widely consumed beverages throughout the world, due to its pleasant taste, aroma, stimulant effect and health benefits $[3,4]$.

Coffee is a rich source of alkaloids such as caffeine, trigonelline, theobromine, theophylline and their profile in green coffee beans is important and helpful to know the quality of coffee brew $[4,5]$. The stimulant effect of coffee makes it one of the most popular beverages in the world is due to the presence of caffeine (1,3,7-trimethylxanthine). Although more than eighty coffee species have been identified worldwide [5], only two coffee species: Coffea arabica (known as Arabica coffee) and Coffea canephora (popularly named as Robusta coffee) are economically important. Arabica and Robusta coffees are different in their chemical composition including their caffeine level [5].

Arabica coffee is considered to be a higher quality bean, prized for its complex aroma [6] and is usually the most expensive one in the world market. Arabica coffee is grown in about 80 tropical and sub-tropical countries. The majority of these countries supply the product to world market. Ethiopia is among these countries which heavily depend on coffee exports for foreign exchange earnings. About $40 \%$ of its export is coffee [7]. The Coffea arabica strain is Ethiopia's original coffee plant and the only one still grown in the country. Ethiopia occupies a unique place in the world with an impressive selection of Arabica coffee varieties with distinct flavor profiles. These varieties have diverse tastes, depending on their geographical origin. Factors including genetic properties, altitude, climate and soil type may have been contributed

*Corresponding author. E-mail: mesfinredi@yahoo.com; mesfin.redi@aau.edu.et

This work is licensed under the Creative Commons Attribution 4.0 International License 
to the unique characteristics of each variety. Consequently there is a price differential for Ethiopian coffees that is determined, among others, by their region of origin [8].

These factors are believed to influence coffees' characteristics: caffeine content, flavor or aroma [9]. Specially, the altitude at which coffee is grown plays a major role in determining the quality of the green coffee bean, because there is less oxygen, coffee plants grown at higher altitudes take longer time to mature than plants grown at lower altitudes. This allows the flavors to develop more fully and produces beans that are delicate and flavorful [10]. High altitudes grown coffee beans usually have a high density than low altitudes grown coffee beans. Recently Brazilian researchers after screening 300 Ethiopian coffee plants discovered three naturally decaffeinated varieties, which they named AC1, AC2 and AC3. Analysis of these varieties showed they contain less than $0.07 \%$ caffeine compared to the caffeine found in natural coffee beans [4].

Determination of concentrations of caffeine in green coffee beans is important for the coffee industry as these compounds determine the flavor and ultimately, the quality of the final coffee beverage. Firstly, the caffeine is associated with the bitterness of the coffee. Secondly, the consumption of coffee and the constituent caffeine have been associated with several physiological effects. Stimulation of the central nervous system, acute elevation of blood pressure, gastrointestinal noncompliance and diuresis has been ascribed to the consumption of caffeine. Some studies have also indicated a significant correlation between high caffeine intake from coffee and the risk of spontaneous abortion. Caffeine has been reported to have some health benefits, such as the prevention of type 2 diabetes mellitus by impairing glucose tolerance, decreasing insulin sensitivity and increasing energy expenditure and weight loss. Some studies have also associated caffeine intake with the prevention of Parkinson's disease [8]. The caffeine level in green coffee beans generally ranges from $0.6-3 \%(\mathrm{w} / \mathrm{w})$ where the highest amount is reported in the Robusta variety. According to studies, the caffeine content of coffee is unaffected by the roasting process, where it imparts its characteristic bitter taste in the final beverage. These studies suggests that, although the roasting process occurs well above the sublimation temperature of caffeine, during it only a small percentage of caffeine vanishes, which is overbalanced by the organic weight loss to maintain the percentage of caffeine per dry weight of coffee nearly constant [8].

Many analytical methods have been developed for the quality control of products containing caffeine: liquid chromatography-particle beam/electron ionization mass spectrophotometry [11], liquid chromatography-tandem mass spectrometry [12], near infrared spectroscopy [13], near infra-red reflectance spectroscopy [14], gas chromatography [15] and fluorescence polarization immunoassays [16].

The caffeine level in coffee samples is determined by various analytical methods. Quantitative determination of caffeine in large number of samples needs an accurate and rapid method. The complete extraction of caffeine from test samples and removal of interfering substances varies from method to method. Therefore, choosing the right analytical method is essential for the accurate determination of caffeine in test samples. There have been numerous reports on the determination of caffeine in coffee samples following different analytical methods: gas chromatography $[15,17,18]$, electrochemical methods such as voltammetry [19], and spectroscopic techniques including nuclear magnetic resonance spectroscopy [20], near infrared [21], high performance liquid chromatography [5, 8, 22, 23], UV-Vis spectroscopy [4, $7,24,25]$ and fluorescence spectroscopy [26]. However, there are only limited reports available on the comparative study of caffeine determination by different analytical methods for a given set of samples $[5,23]$. Therefore, the aim of the present study is comparative determination of caffeine level in green coffee bean samples from Southwest Ethiopia by UV-Vis spectrophotometry and high performance liquid chromatography and to determine the correlation between caffeine contents of green coffee beans and altitudes at which the coffee plants grew. 


\section{EXPERIMENTAL}

\section{Chemicals}

Dichloromethane (Aldrich, Germany), $\mathrm{Na}_{2} \mathrm{SO}_{4}$ (Sigma-Aldrich, UK), standard caffeine (Merck J.T. Baker Chemical Company, USA), theobromine (Sigma-Aldrich, Italy), trigonelline hydrochloride (Sigma-Aldrich, Switzerland) and theophylline (Sigma-Aldrich, Switzerland) were used as received. HPLC grade acetonitrile and formic acid were supplied by SigmaAldrich (Johannesburg, South Africa) and lead acetate from (BDH Chemicals, Poole, England). Distilled water was used throughout the study.

\section{Instruments and apparatus}

The laboratory apparatus and instrument used in this study are the following: $300 \mu \mathrm{m}$ sieve (Chicago, ILL 60656 USA), shaker (KS125 basic, Germany), centrifuge (Janetzki, model T32c, Olympus, Japan) and Electronic balance (SP 1500, USA). Absorption spectra were obtained using a double-beam spectrophotometer (Lambda 950-UV-Vis-NIR, PerkinElmer, UK) interfaced with a computer using $2 \mathrm{~nm}$ resolution in a $1 \mathrm{~cm}$ path length quartz cell. High performance liquid chromatograph (HPLC) (Agilent 1260 Infinity, Germany) coupled to a diode array detector (DAD) was also used for caffeine determination.

\section{Green coffee bean samples}

Green coffee bean samples were collected from Southwest region of Ethiopia grown at different altitudes. A total of 45 green coffee bean samples were collected from the coffee plant grown at high $(>1850 \mathrm{~m})$, medium $(1650-1850 \mathrm{~m})$ and low $(1144-1650 \mathrm{~m})$ altitudes from different places. From each site $300 \mathrm{~g}$ of green coffee sample were collected. All of the green coffee bean samples were obtained from ripe coffee cherries processed either by washing or sun drying techniques, depending on the practices in areas from where samples were collected. All the samples were from the same harvest season and were collected throughout April 2016. All the samples were stored separately in plastic bags under airtight conditions and transported to the laboratory for chemical analysis.

\section{Preparation of standard solution for UV-Vis spectrophotometry}

Caffeine stock solution $(1000 \mathrm{mg} / \mathrm{L})$ was prepared by dissolving $100 \mathrm{mg}$ of pure caffeine in 100 $\mathrm{mL}$ of dichloromethane and prepared intermediate solution $(500 \mathrm{mg} / \mathrm{L})$ in $50 \mathrm{~mL}$ of volumetric flask. Then, by taking $1,2,4,6,8$ and $10 \mathrm{mg} / \mathrm{L}$ caffeine working solutions in to six $25 \mathrm{~mL}$ volumetric flasks calibration solutions were prepared. The absorption spectra of the solutions were recorded in the wavelength range $200-500 \mathrm{~nm}$. These procedures were repeated three times for the same concentrations then the mean value was taken. Finally, from the absorbance, the molar decadic absorption coefficients $(\varepsilon)$ of caffeine in dichloromethane were obtained.

\section{Calibration curve of caffeine in dichloromethane for UV-Vis spectrophotometry}

The molar decadic absorption coefficient of caffeine in dichloromethane was obtained by measuring the intensity of the absorption of a series of concentration of caffeine in dichloromethane. Caffeine concentration of $\left(0.0052-0.0515 \mathrm{~mol} / \mathrm{m}^{3}\right)$ was measured at $275 \mathrm{~nm}$ using UV-Vis spectrophotometer. Then the absorbance versus concentration graph was constructed to validate the UV-Vis absorption of caffeine in terms of linearity, sensitivity, precision and for calibration purpose to determine the caffeine content of various coffee samples. From the calibration curve, the calibration equation obtained was: $\mathrm{y}=9.8411 \mathrm{x}+$ $0.0024, \mathrm{R}^{2}=0.9997$, where $\mathrm{y}$ is absorbance, $\mathrm{x}$ is concentration of caffeine and $\mathrm{R}$ is the linear 
regression coefficient. This equation indicated that the present study was carried out according to the Beer's law ranges in terms of linearity, sensitivity and precision of the method. Thus, the proposed method allowed for determination of caffeine in coffee samples. The calibration curve was observed for a wide concentration range, which is convenient for the determination of caffeine in coffee beans. The molar decadic absorption coefficient of caffeine in dichloromethane were calculated based on the Beer Lambert's law and obtained value of 1000 $\mathrm{m}^{2} \mathrm{~mol}^{-1}$ at the maximum absorption wavelength, $275 \mathrm{~nm}$.

\section{Coffee sample preparation for UV-Vis analysis}

The extraction of caffeine from green coffee bean samples in to water was carried out by the reported method [24, 25]. For each sample, $20 \mathrm{~g}$ of the green coffee bean samples were ground and screened through $300 \mu \mathrm{m}$ sieve to get a uniform mixture and stored at room temperature. An accurately weighed amount $(1 \mathrm{~g})$ of coffee sample was added to $100 \mathrm{~mL}$ of distilled water. The mixture was stirred for one hour and heated gently up to $70{ }^{\circ} \mathrm{C}$ to extract caffeine easily from the sample into the solution. The solution was filtered with Whatman filter paper to get a clear solution. Then the filtrate was stored in the fridge for liquid-liquid extraction.

\section{Liquid-liquid extraction of caffeine for UV-Vis analysis}

The extraction of caffeine from the aqueous solution in to dichloromethane was carried out by the reported method [24, 25]. The aqueous coffee extract was mixed with $25 \mathrm{~mL}$ dichloromethane for the extraction of caffeine from water extract. The solution was stirred for about $10 \mathrm{~min}$ and caffeine was extracted from the aqueous solution in to dichloromethane using $250 \mathrm{~mL}$ separatory funnel. The extraction of caffeine was performed three times $(25 \mathrm{~mL}$ each $)$ with a total volume of $75 \mathrm{~mL}$ dichloromethane. The contents of caffeine in the $4^{\text {th }}$ extract were found negligible. The extracted caffeine was stored in a volumetric flask for quantitative determination of caffeine using UV-Vis spectrophotometer. The total content of caffeine in coffee samples was determined from the spectrum of combined extracts. The efficiency of dichloromethane to extract caffeine from coffee beans is $98-99 \%$ [24] because caffeine is more soluble in dichloromethane $\left(140 \mathrm{mg} \cdot \mathrm{mL}^{-1}\right)$ than it is in water $\left(22 \mathrm{mg} \cdot \mathrm{mL}^{-1}\right)$ [25].

\section{Preparation of standard solution for HPLC analysis}

Caffeine stock solution (100 mg/L) was prepared by dissolving $5.00 \mathrm{mg}$ of pure caffeine in 50 $\mathrm{mL}$ boiling distilled water. Working standards of 1, 10, 30, 60 and $100 \mathrm{mg} / \mathrm{L}$ caffeine were prepared in $10 \mathrm{~mL}$ volumetric flasks by serial dilution with the boiling distilled water.

\section{Extraction of caffeine for HPLC analysis}

Alkaloids were extracted from the green coffee powders by using the procedure described by [8]. Briefly, a $0.200 \mathrm{~g}$ portion of each green coffee bean sample powder, weighed directly into a centrifuge tube, was extracted with $5.00 \mathrm{~mL}$ of boiling distilled water by shaking for $30 \mathrm{~min}$ on a shaker at $200 \mathrm{rpm}$. The mixture was centrifuged for $5 \mathrm{~min}$ at $3600 \mathrm{rpm}$, where after the supernatant was decanted carefully into a second centrifuge tube. The residue was returned to the tube and extracted for a second time with $5.00 \mathrm{~mL}$ of boiling water. After combination of the supernatants, the volume was adjusted to $10.0 \mathrm{~mL}$. A $1.50 \mathrm{~mL}$ portion of the extract was treated with $30 \mu \mathrm{L}$ of $20 \%(\mathrm{w} / \mathrm{v})$ aqueous lead acetate solution to precipitate out polysaccharides, proteins and other colloidal material from the extract solution [8]. After centrifuging the mixture for 5 min the supernatant was filtered directly into a chromatographic vial through a $0.45-\mu \mathrm{m}$ syringe filter for chromatographic analysis. 


\section{Determination of caffeine by HPLC}

HPLC system, coupled to a diode array detector (DAD), was used to determine the alkaloids in the green coffee extracts. After introduction of the sample $(5 \mu \mathrm{L})$, separation was achieved on a reversed phase C8 column (Supelco, $15 \mathrm{~cm} \times 4.6 \mathrm{~mm}, 5 \mu \mathrm{m}$, USA) maintained at $25{ }^{\circ} \mathrm{C}$ in a column thermostat. The analysis was carried out under isocratic conditions using $90 \%$ deionized water (acidified as $0.1 \%$ aqueous formic acid) and $10 \%$ acetonitrile at a flow rate of $0.3 \mathrm{~mL}$ $\mathrm{min}^{-1}$. The mobile phase was allowed to flow for $3 \mathrm{~min}$ between each analysis to wash and recondition the column. Chromatographic data for caffeine were collected at $280 \mathrm{~nm}$. In addition, the DAD was set to collect UV-Vis spectral data in the wavelength range 200-400 nm. Peak identification was performed by comparing the retention times and the UV-Vis spectral profiles of analytes to those of pure standards. Quantitative determination of caffeine was done after constructing calibration curves from the chromatographic peak areas obtained after analysis of standard solutions of caffeine. A calibration curve was obtained using five different concentrations of caffeine in the range of $1-100 \mathrm{mg} / \mathrm{L}$ for the determination of the caffeine content of coffee extracts. The equation of the calibration curve was obtained from the resulting peak area versus concentration. The caffeine levels of the samples were calculated from the regression equation of the standards $\mathrm{y}=5.0323 \mathrm{x}-1.2166, \mathrm{R}^{2}=0.9997$ where $\mathrm{y}$ is peak area of caffeine at $280 \mathrm{~nm}$, $x$ is concentration of caffeine and $\mathrm{R}$ is the linear regression coefficient. All samples were analyzed in triplicate from three separate extracts, and each of the triplicate samples was also analyzed by HPLC.

\section{RESULTS AND DISCUSSION}

\section{Determination of caffeine content of green coffee beans by UV-Vis spectrophotometry}

A UV-Vis spectrophotometric method cannot be used directly for the determination of caffeine in green coffee beans owing to the matrix effect of UV-Vis absorbing substances in the sample matrix. This effect is also clearly seen in the spectral bands of caffeine in green coffee beans extract in distilled water. Hence, it is not suitable to determine the percentage of caffeine in green coffee beans due to overlapping of these interfering bands [25]. In order to overcome this difficulty caffeine in the green coffee beans was extracted from the aqueous solution using dichloromethane. Dichloromethane is the most commonly employed solvent for extraction of caffeine from green coffee beans [4]. After extraction, the absorbance of the solution was measured using UV-Vis spectrophotometer. The caffeine levels of the samples were calculated by using Beer-Lambert's law. UV-Vis spectrum of standard caffeine in dichloromethane and representative UV-Vis spectra of caffeine extracted in to dichloromethane from the aqueous extract of green coffee beans from coffee plant grown at a high altitude (Wolaita Kocho, 2950 masl) and at a low altitude (Kefa Zone Bonga, 1598 masl) are shown in Figure 1.

The data on caffeine contents of 45 green coffee beans samples obtained by UV-Vis spectrophotometry are presented in Table 1 . The caffeine content in all the green coffee beans samples was observed in the range $0.6-1.2 \%(\mathrm{w} / \mathrm{w})$. There was a significant difference $(\mathrm{p}<$ 0.05 ) in caffeine contents among all the green coffee beans samples. This indicated that the caffeine content of green coffee beans obtained from the plants growing at different altitudes of geographical location is significantly different. In support to this study different value of caffeine contents in green coffee beans have been reported by the previous researchers $[6,8,24-$ 27]. For example, an average value of $1.10 \%(\mathrm{w} / \mathrm{w})$ by HPLC methods for 42 Ethiopian coffee samples [6], and in the range $0.96-1.23 \%(\mathrm{w} / \mathrm{w})$ for Arabic green coffee beans [27] were reported for their caffeine contents. There are more reports that describe the average value of caffeine to be less than $1.5 \%(\mathrm{w} / \mathrm{w})$ for Arabica coffee [4]. Moreover, the caffeine content in Ethiopian Arabica coffee grown in Bench Maji, Gediyo Yirgachefe, Tepi, and Godere has been

Bull. Chem. Soc. Ethiop. 2018, 32(1) 
determined by UV-Vis spectrophotometry to be $1.1,1.01,1.07$, and $1.19 \%$ (w/w), respectively and fifteen coffee bean samples from Ethiopian Hararghe in the range of $0.6-0.9 \%(\mathrm{w} / \mathrm{w})$ [25]. Therefore, these values are in reasonable degree of agreement with the findings of the present work.

In summary, all the coffee samples have the caffeine level in the range of the caffeine contents of different Arabica coffee reported previously [6, 8, 24-27]. The variation in caffeine level of green coffee beans samples may be due to geographical origins which might have different altitude, soil type, rain fall and other agricultural as well as environmental conditions.

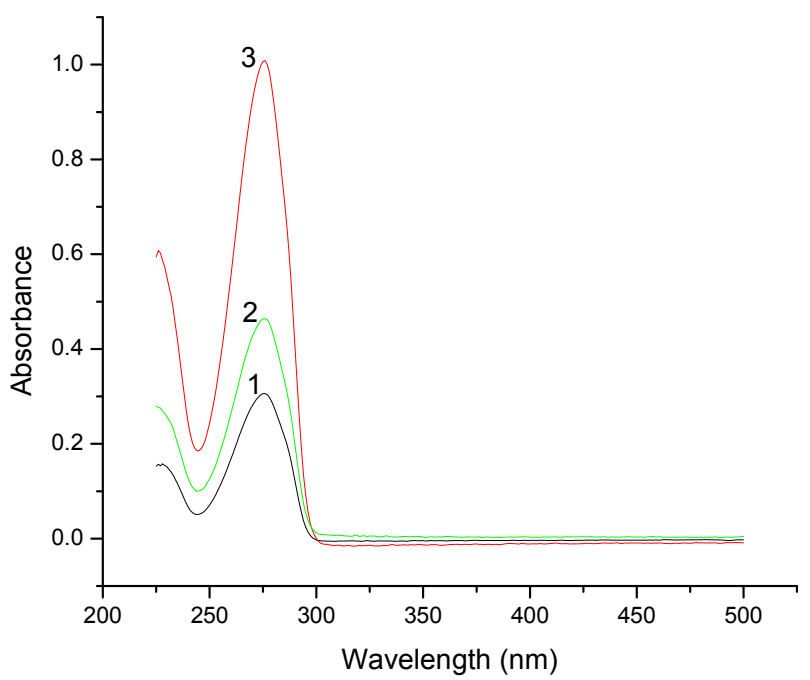

Figure 1. UV-Vis spectra of caffeine extracted in to dichloromethane from the aqueous extract of green beans from the coffee plant from (1) Wolaita Kocho (entry 2, Table 1) grown at high altitude (2950 masl, caffeine content $0.68 \pm 0.01 \%$ w/w), (2) Kefa Zone Bonga (entry 45, Table 1) grown at low altitude (1598 masl, caffeine content $1.16 \pm 0.02 \%$ $\mathrm{w} / \mathrm{w})$ and (3) standard caffeine dissolved in dichloromethane $(35 \mathrm{mg} / \mathrm{L})$.

Correlation between caffeine contents of green coffee beans and the altitudes of the coffee plants

In this research a significant variations in the concentration of caffeine in the green coffee bean samples were observed depending on the level of altitudes at which the coffee plants grew. A correlation was established between caffeine contents of green coffee beans and the altitudes of the coffee plants. The plot of caffeine contents and the altitude at which the coffee plants were grown is shown in Figure 2. A moderate negative correlation $(\mathrm{R}=0.5463)$ was found between the caffeine contents in green coffee beans and the altitudes at which the coffee plants were grown. This result clearly indicates that the caffeine contents are lower in the green coffee beans obtained from the plant grown at higher altitudes while the caffeine contents are higher in the green coffee beans obtained from the plant grown at lower altitudes. This is the first study directly correlating the caffeine contents and the altitudes of coffee plants in Ethiopia. 
Table 1 . The mean caffeine content $(\% \mathrm{w} / \mathrm{w} \pm \mathrm{SD})$ in green coffee beans and altitudes of the coffee plants.

\begin{tabular}{|c|c|c|c|}
\hline No. & Coffee bean samples & Altitude (masl) & Mean $\pm \mathrm{SD} \%(\mathrm{w} / \mathrm{w})$ \\
\hline 1 & Malokoza Tata Mabeteria Bet & 2115 & $0.62 \pm 0.02$ \\
\hline 2 & Wolaita Kocho & 2950 & $0.68 \pm 0.01$ \\
\hline 3 & Malokoza Mashro Kundilo, sample b & 2100 & $0.64 \pm 0.02$ \\
\hline 4 & Mizanteferi (chaka) & 2137 & $0.68 \pm 0.02$ \\
\hline 5 & Dawro -waro, 2 & 1800 & $0.67 \pm 0.02$ \\
\hline 6 & Bokray & 1950 & $0.67 \pm 0.02$ \\
\hline 7 & Malokoza Gergeda kebele & 2400 & $0.72 \pm 0.01$ \\
\hline 8 & Malokoza, $\mathrm{d}$ & 2115 & $0.73 \pm 0.02$ \\
\hline 9 & Malokoza, c & 2115 & $0.80 \pm 0.04$ \\
\hline 10 & Shishndea-Kefa & 1930 & $0.71 \pm 0.03$ \\
\hline 11 & Tabo-Malokoza & 2508 & $0.73 \pm 0.01$ \\
\hline 12 & Malokoza Tarki sere, sample 2 & 1730 & $0.75 \pm 0.02$ \\
\hline 13 & Malokoza Kundilo, sample a1 & 1700 & $0.69 \pm 0.01$ \\
\hline 14 & Malokoza Kundilo, sample a3 & 1800 & $0.68 \pm 0.02$ \\
\hline 15 & Malokoza Masharo Kundilo, sample b1 & 1840 & $0.68 \pm 0.02$ \\
\hline 16 & Malokoza Borda (Ato. Endale Assefaw) & 1800 & $0.68 \pm 0.02$ \\
\hline 17 & Koza Dilawalcha & 2400 & $0.72 \pm 0.02$ \\
\hline 18 & Malokoza Masharo Kudilo & 1750 & $0.73 \pm 0.04$ \\
\hline 19 & Hidasse Geda & 1268 & $0.74 \pm 0.04$ \\
\hline 20 & Malokoza Meyzelo (Ato. Tilaargachew) & 1700 & $0.66 \pm 0.02$ \\
\hline 21 & Malokoza Laha market & - & $0.67 \pm 0.02$ \\
\hline 22 & Waro-Dawro, 1 & 1800 & $0.75 \pm 0.02$ \\
\hline 23 & Sebat Bet Gurage & 1907 & $0.75 \pm 0.02$ \\
\hline 24 & Wolaita Sodo market & - & $0.74 \pm 0.02$ \\
\hline 25 & Malokoza, b & 2115 & $0.75 \pm 0.02$ \\
\hline 26 & Meletata Mabeteria & 1179 & $0.76 \pm 0.05$ \\
\hline 27 & Malokoza Kundilo sample, 2a & 1144 & $0.78 \pm 0.03$ \\
\hline 28 & Dekulilu Tayarea Koza & 1500 & $0.83 \pm 0.02$ \\
\hline 29 & MalokozaMeyzelo (Ato. Ayelekuma) & 1600 & $0.84 \pm 0.03$ \\
\hline 30 & Kasha-chida & 1200 & $0.86 \pm 0.01$ \\
\hline 31 & Wato Asendabo & 1600 & $0.82 \pm 0.02$ \\
\hline 32 & Malokoza Laha market (main) & - & $0.86 \pm 0.03$ \\
\hline 33 & Malokoza Pircha kebele, sample1a & 1400 & $0.87 \pm 0.02$ \\
\hline 34 & Malokoza Laha market & - & $0.77 \pm 0.02$ \\
\hline 35 & Malokoza (koza kebele) & 1600 & $0.80 \pm 0.03$ \\
\hline 36 & Malokoza, a & 2115 & $0.70 \pm 0.02$ \\
\hline 37 & Wolaita Sodo & 1750 & $0.84 \pm 0.06$ \\
\hline 38 & Jimma Zone & 1719 & $0.87 \pm 0.02$ \\
\hline 39 & Malokoza Laha striped & 1434 & $0.92 \pm 0.03$ \\
\hline 40 & Malokoza Masharo kebele, sample 1 & 1513 & $0.89 \pm 0.03$ \\
\hline 41 & Koisha-konta & 1200 & $0.92 \pm 0.04$ \\
\hline 42 & Jimma Ber & 1600 & $0.98 \pm 0.02$ \\
\hline 43 & Asendabo & 1554 & $0.86 \pm 0.02$ \\
\hline 44 & Silte Kafa & 1500 & $1.04 \pm 0.02$ \\
\hline 45 & Kefa Zone Bonga & 1598 & $1.16 \pm 0.02$ \\
\hline
\end{tabular}

"masl - meters above sea level. It should be noted that Sample No. 21, 24, 32 and 34 were obtained from the local markets and hence their precise altitudes were not known. 


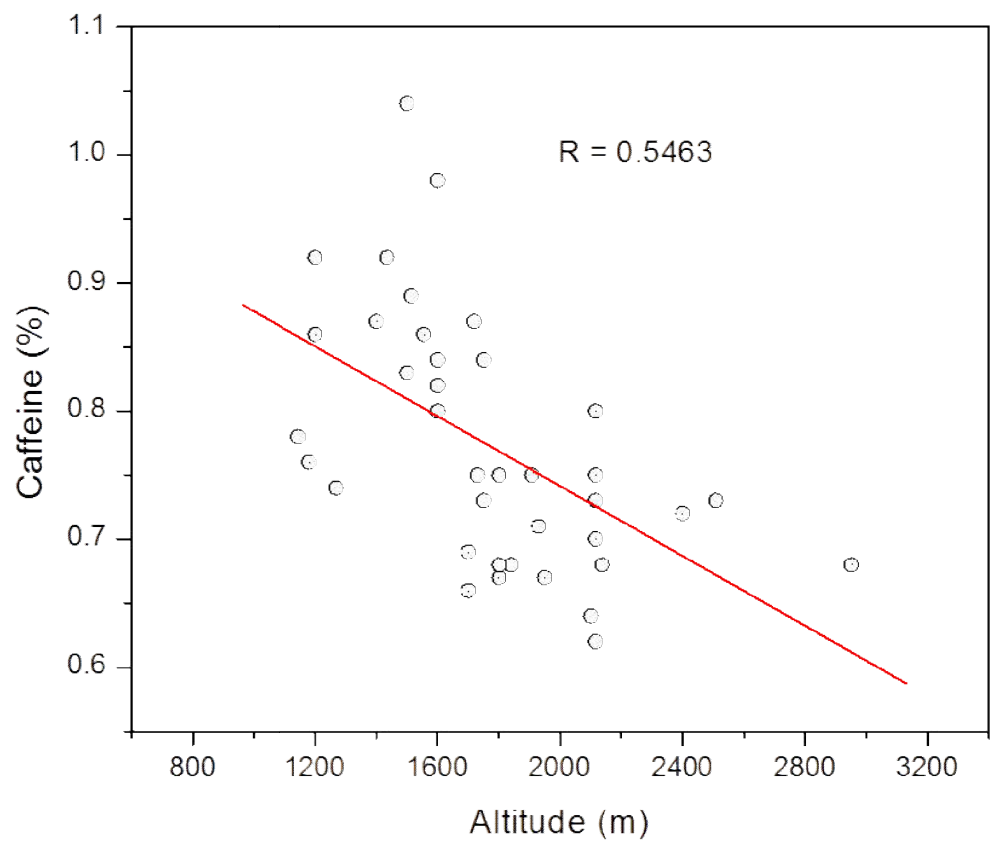

Figure 2. Correlation between caffeine content of green coffee beans and altitude of the coffee plants.

Determination of caffeine in green coffee beans by HPLC method

The aqueous extracts of the green coffee beans samples were analyzed to determine the concentrations of caffeine. Analysis of a standard mixture $(100 \mu \mathrm{L}$ each $)$ of the four alkaloids by HPLC provided well separated peaks within 7 min (Figure 3). Mehari et al. [8] reported a HPLC method for the separation of trigonelline, theobromine, theophylline and caffeine within $7 \mathrm{~min}$. Theophylline was not detected in any of the green coffee bean samples analyzed in the present study. Mehari et al. [8] reported that theophylline was not present in green Arabica coffee beans from Africa, Asia and America. However, trigonelline, theobromine and caffeine were detected in the green coffee beans samples. A representative HPLC chromatogram of caffeine from coffee plant from a high altitude and from a low altitude is shown in Figure 4. Figure 4 shows HPLC chromatogram of caffeine from coffee plant from (1) Wolaita Kocho (entry 2, Table 1) grown at high altitude (2950 masl, caffeine content $0.68 \pm 0.01 \% \mathrm{w} / \mathrm{w}$ ) and (2) Kefa Zone Bonga (entry 45, Table 1) grown at low altitude (1598 masl, caffeine content $1.16 \pm 0.02 \% \mathrm{w} / \mathrm{w}$ ).

The concentration $(\% \mathrm{w} / \mathrm{w})$ of the caffeine determined in the green coffee beans is given in Table 2. Samples were analyzed in triplicates from three separate extracts, and each individual triplicate sample was analyzed by HPLC. In the present study, the caffeine level recorded in the coffee bean samples 0.60 to $1.2 \%(\mathrm{w} / \mathrm{w})$ were in line with the previously reported caffeine levels of 0.6 to $1.5 \%$ in Arabica coffee $[6,8,24,25]$. 


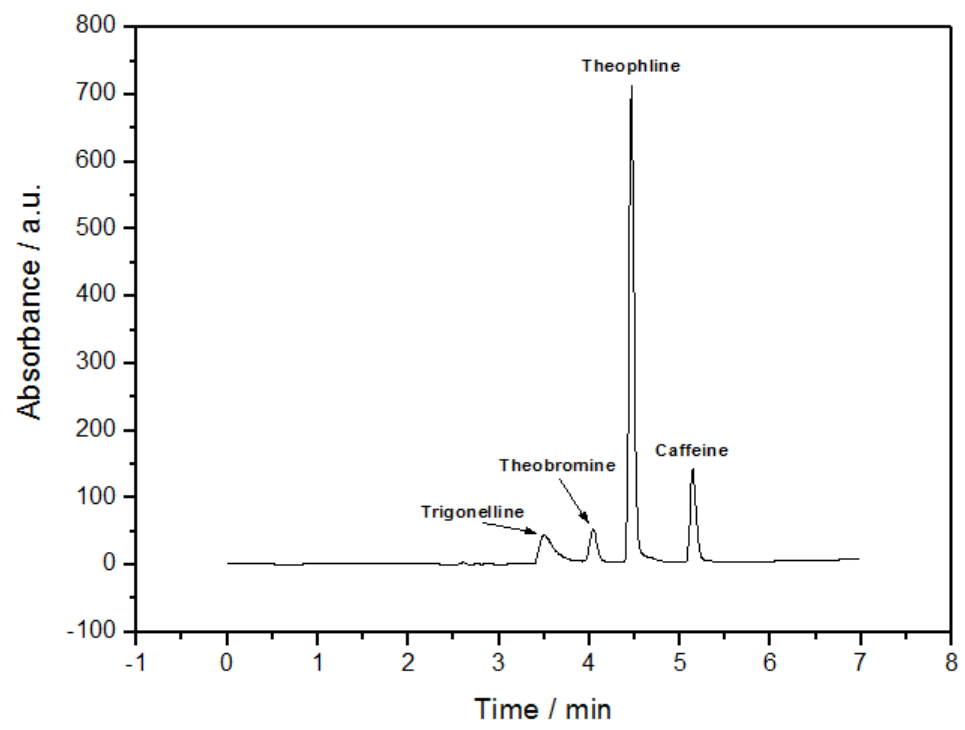

Figure 3. HPLC chromatogram of a mixture of standard solutions of the four alkaloids present in the green coffee beans. A mixture of the four alkaloids $(100 \mu \mathrm{L}$ each) was injected to the HPLC system, coupled to a diode array detector (DAD). Separation was achieved on a reversed phase C8 column (Supelco, $15 \mathrm{~cm} \times 4.6 \mathrm{~mm}, 5 \mu \mathrm{m}$, USA) maintained at $25{ }^{\circ} \mathrm{C}$ in a column thermostat. The analysis was carried out under isocratic conditions using $90 \%$ deionized water (acidified as $0.1 \%$ aqueous formic acid) and $10 \%$ acetonitrile at a flow rate of $0.3 \mathrm{~mL} \mathrm{~min}^{-1}$.

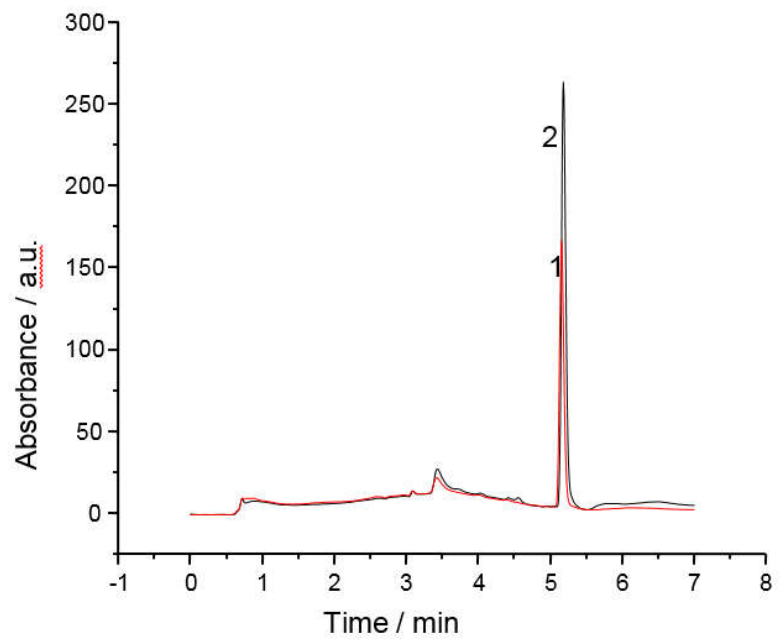

Figure 4. HPLC chromatograms of aqueous extract of caffeine from green beans from the coffee plant from (1) Wolaita Kocho (entry 2, Table 1) grown at high altitude (2950 masl, caffeine content $0.68 \pm 0.01 \% \mathrm{w} / \mathrm{w}$ ) and (2) Kefa Zone Bonga (entry 45, Table 1) grown at low altitude (1598 masl, caffeine content $1.16 \pm 0.02 \% \mathrm{w} / \mathrm{w})$. A $5 \mu \mathrm{L}$ aqueous extract of caffeine from green coffee beans was injected to the HPLC system, coupled to a diode array detector (DAD). Other conditions are the same as given in Figure 3.

Bull. Chem. Soc. Ethiop. 2018, 32(1) 
Table 2. Comparison of caffeine content $\%(\mathrm{w} / \mathrm{w})$ obtained by UV-Vis spectrophotometric and high performance liquid chromatographic methods.

\begin{tabular}{|c|c|c|c|c|}
\hline \multirow[t]{2}{*}{ No. } & \multirow[t]{2}{*}{ Sample type } & \multicolumn{2}{|c|}{ Method } & \multirow[t]{2}{*}{ Statistical analysis paired t-test at the 0.05 level } \\
\hline & & UV-Vis & HPLC & \\
\hline 1 & Wolaita Kocho & 0.68 & 0.66 & $\begin{array}{l}\text { The two means are not significantly different } \\
t_{\text {exp }}<t_{\text {crit }}(0.26<4.3)\end{array}$ \\
\hline 2 & MKmk sb & 0.64 & 0.62 & $\begin{array}{l}\text { The two means are not significantly different } \\
t_{\text {exp }}<t_{\text {crit }}(0.35<4.3)\end{array}$ \\
\hline 3 & MKtm Bet & 0.62 & 0.60 & $\begin{array}{l}\text { The two means are not significantly different } \\
\mathrm{t}_{\text {exp }}<\mathrm{t}_{\text {crit }}(0.23<4.3)\end{array}$ \\
\hline 4 & $\begin{array}{l}\text { Sebat Bet } \\
\text { Gurage }\end{array}$ & 0.75 & 0.73 & $\begin{array}{l}\text { The two means are not significantly different } \\
t_{\text {exp }}<t_{\text {crit }}(0.16<4.3)\end{array}$ \\
\hline 5 & Malokoza b & 0.75 & 0.73 & $\begin{array}{l}\text { The two means are not significantly different } \\
t_{\exp }<t_{\text {crit }}(0.26<4.3)\end{array}$ \\
\hline 6 & $\begin{array}{l}\text { Wolaita Sodo } \\
\text { market }\end{array}$ & 0.74 & 0.71 & $\begin{array}{l}\text { The two means are not significantly different } \\
\mathrm{t}_{\exp }<\mathrm{t}_{\text {crit }}(0.25<4.3)\end{array}$ \\
\hline 7 & Asendabo & 0.86 & 0.84 & $\begin{array}{l}\text { The two means are not significantly different } \\
t_{\text {exp }}<t_{\text {crit }}(0.35<4.3)\end{array}$ \\
\hline 8 & Silite Kefa & 1.04 & 0.93 & $\begin{array}{l}\text { The two means are not significantly different } \\
t_{\text {exp }}<t_{\text {crit }}(0.27<4.3)\end{array}$ \\
\hline 9 & $\begin{array}{l}\text { Kefa zone } \\
\text { Bonga }\end{array}$ & 1.16 & 1.09 & $\begin{array}{l}\text { The two means are not significantly different } \\
\mathrm{t}_{\text {exp }}<\mathrm{t}_{\text {crit }}(0.30<4.3)\end{array}$ \\
\hline
\end{tabular}

Comparison of caffeine contents in green coffee beans obtained by UV-Vis and HPLC methods

In this study two different procedures were used for the extraction of caffeine from the green coffee beans because the extraction procedures reported for the UV-Vis spectrophotometric method [24, 25] is slightly different from the HPLC method [8]. Basically the two procedures are not different as such, extraction in water at $70{ }^{\circ} \mathrm{C}$ for one hour for $\mathrm{UV}$ analysis and boiling water for $30 \mathrm{~min}$ for HPLC analysis. In both procedures the caffeine is extracted in to hot water at different temperature by stirring/shaking for different times. Because of the temperature difference the stirring/shaking time was different. At lower temperature $\left(70{ }^{\circ} \mathrm{C}\right)$ the time was 60 min for the UV method and at higher temperature (boiling water, $100{ }^{\circ} \mathrm{C}$ ) the time was shorter, $30 \mathrm{~min}$. The caffeine contents of nine green coffee bean samples we determined by the two methods are not significantly different as shown by the paired t-test. Therefore we can conclude that the caffeine extraction efficiency of the two methods is not significantly different. Furthermore, it should also be noted that the aqueous extract of caffeine from the green coffee beans for the HPLC method was further treated with aqueous lead acetate solution to precipitate out polysaccharides, proteins and other colloidal material from the extract solution [8]. This treatment was done to avoid contamination of chromatographic column. No such treatment was required for the UV method. The caffeine in the aqueous extract of the green coffee beans was selectively extracted in to dichloromethane for the UV-Vis measurements. The sample preparation for UV-Vis method involves the use of organic solvent (dichloromethane) while lead acetate is used in sample preparation for the HPLC method. Therefore, both the methods are non-green to some extent. In contrast to this the UV-Vis method is much faster than the HPLC method.

The caffeine level obtained by UV-Vis spectrophotometric method was compared with those obtained by HPLC method (Table 2). The caffeine contents were found in the range of $0.62-1.2 \%(\mathrm{w} / \mathrm{w})$ by UV-Vis and $0.60-1.1 \%(\mathrm{w} / \mathrm{w})$ by HPLC methods. Statistical analysis (paired t-test at 0.05 level) was applied to the data obtained by the two methods which indicated that there is no significant differences in the caffeine contents obtained by the two methods. Similarly Gopinandhan et al. [5] determined caffeine content in eight green coffee bean samples 
by UV-Vis spectrophotometric method and compared it with HPLC method. They concluded that there was no significant difference between the mean caffeine values obtained by the two methods. On the contrary, Wanyika et al. [23] compared caffeine level in a variety of beverages collected from Kenyan market including coffee drink and reported that spectrophotometric method yielded higher caffeine value than HPLC method. However, the amount of caffeine that enters the human system through drinking of coffee beverages would better be determined by the HPLC method since the said beverages are prepared using pure water as the solvent. Results from the present method are in good agreement with those obtained by previously reported studies (Table 3 ).

Table 3. Comparison of results of the present method with the literature methods.

\begin{tabular}{|l|l|l|l|}
\hline Methods & $\begin{array}{l}\text { Caffeine } \%(\mathrm{w} / \mathrm{w}) \\
(\text { no. of samples) }\end{array}$ & $\begin{array}{l}\text { Country of } \\
\text { coffee origin }\end{array}$ & References \\
\hline UV-Vis spectrophotometry & $0.6-0.9,(\mathrm{n}=15)$ & Ethiopia & {$[25]$} \\
\hline UV-Vis spectrophotometry & $1.0-1.2,(\mathrm{n}=5)$ & Ethiopia & {$[24]$} \\
\hline UV-Vis spectrophotometry & $0.97-1.5,(\mathrm{n}=4)$ & Ethiopia & {$[4]$} \\
\hline Derivative UV-Vis spectrophotometry & $0.8-2.8,(\mathrm{n}=5)$ & Vietnam & {$[28]$} \\
\hline HPLC & $0.87-1.4,(\mathrm{n}=99)$ & Ethiopia & {$[8]$} \\
\hline HPLC and UV-Vis & $1.64-12.6,(\mathrm{n}=3)$ & Kenya & {$[23]$} \\
\hline HPLC and UV-Vis & $0.89-1.5,(\mathrm{n}=8)$ & India & {$[5]$} \\
\hline HPLC and UV-Vis & $0.6-1.2,(\mathrm{n}=48)$ & Ethiopia & Present work \\
\hline
\end{tabular}

\section{CONCLUSION}

UV-Vis spectrophotometry and HPLC methods were successfully applied for the determination of the caffeine content in green coffee beans extracted by dichloromethane and by hot distilled water, respectively. In this study, significant variations in the concentrations of caffeine in the green coffee bean samples were observed depending on the altitudes at which the coffee plant grows. A moderate negative correlation $(\mathrm{R}=0.5463)$ was found between the caffeine contents in green coffee beans and the altitudes at which the coffee plants were grown. Among the 45 coffee varieties from Southwest Ethiopia, Malokoza Tata Mabterai Bet, Malokoza Masharo Kundilo sample b and Wolaita Kocho can be considered as low in caffeine; these samples were obtained from the coffee plant grown at high altitudes of Southwest Ethiopia. On the other hand the coffee varieties grown at high altitudes in Asendabo, Silite Kefa and Kefa Zone Bonga have high caffeine content. The concentration of caffeine in the green coffee beans was ranged from 0.60 to $1.2 \%(\mathrm{w} / \mathrm{w})$ with no significantly difference between the two methods used for determination of caffeine contents of nine samples. The amount of caffeine available to humans through drinking of coffee is prepared by hot water as the extracting medium. The HPLC method followed in the present study uses hot water for the extraction of caffeine from the green coffee bean samples versus the use of dichloromethane solvent in case of UV-Vis spectrophotometric method. Considering the above points, the HPLC method is precise, accurate and reliable in determining caffeine content in green coffee bean samples while the $\mathrm{UV}-\mathrm{Vis}$ spectrophotometry is simple, rapid, precise and more economical.

\section{ACKNOWLEDGMENTS}

The authors thank the Addis Ababa University for funding their Project used in this study. The authors are also thankful to the Department of Chemistry, Addis Ababa University for providing 
laboratory facilities. Mulu Hogos is also thankful to Ethiopia Police University College, for sponsoring her study.

\section{REFERENCES}

1. Gure, A.; Chandravanshi, B.S.; Godeto, T.W. Metals in green coffee beans from major coffee-growing regions of Ethiopia. Chem. Int. 2017, 3, 359-369.

2. Gure, A.; Chandravanshi, B.S.; Godeto, T.W. Assessment of metals in roasted indigenous coffee varieties of Ethiopia. Bull. Chem. Soc. Ethiop. 2018, 32, 27-38.

3. Ashu, R.; B.S. Chandravanshi, B.S. Concentration levels of metals in commercially available Ethiopian roasted coffee powder and their infusions. Bull. Chem. Soc. Ethiop. 2011, 25, 11-24.

4. Gebeyehu, B.T.; Bikila, S.L. Determination of caffeine content and antioxidant activity of coffee. Am. J. Appl. Chem. 2015, 3, 69-76.

5. Gopinandhan, N.T.; Mallikarjun, B.; Ashwini, M.S.; Basavaraj, K. A comparative study on caffeine estimation in coffee samples by different methods. Int. J. Curr. Res. Chem. Pharm. Sci. 2014, 1, 04-08.

6. Yigzaw, D.; Labuschagne, M.T.; Osthoff, G.; Herselman, L. Variation for green bean caffeine, chlorogenic acids, sucrose and trigonelline contents among Ethiopian Arabica coffee accessions. SINET: Ethiop. J. Sci. 2007, 30, 77-82.

7. Belete, Y.; Belachew, B.; Fininsa, C. Evaluation of bean qualities of indigenous Arabica coffee genotypes across different environments. J. Plant Breed. Crop Sci. 2014, 6, 35-143.

8. Mehari, B.; Redi-Abshiro, M.; Chandravanshi, B.S.; Atlabachew, M.; Combrinck, S.; McCrindle, R. Simultaneous determination of alkaloids in green coffee beans from Ethiopia: Chemometric evaluation of geographical origin. Food Anal. Methods 2016, 9, 1627-1637.

9. Perroneet, D.; Donangelo, C.M.; Farah, A. Fast simultaneous analysis of caffeine, trigonelline, nicotinic acid and sucrose in coffee by liquid chromatography-mass spectrometry. Food Chem. 2008, 110, 1030-1035.

10. Sridevi, V.; Giridhar, P. Changes in caffeine content during fruit development in Coffea canephora grown at different elevations. J. Biol. Earth Sci. 2014, 3, B168-B175.

11. Castro, J.; Pregibon, T.; Chumanov, K.; Marcus, R.K. Determination of catechins and caffeine in proposed green tea standard reference materials by liquid chromatography particle beam/electron ionization mass spectrometry. Talanta 2010, 82, 1687-1695.

12. Choi, E.J.; Bae, S.H.; Park, J.B.; Kwon, M.J.; Jang, S.M.; Zheng, Y.F.; Lee, Y.S.; Lee, S.; Bae, S.K. Simultaneous quantification of caffeine and its three primary metabolites in rat plasma by liquid chromatography-tandem mass spectrometry. Food Chem. 2013, 141, 27352742.

13. Zhang, X.; Li, W.; Yin, B.; Chen, W.; Kelly, D.P.; Wang, X.; Zheng, K.; Du, Y. Improvement of near infrared spectroscopic (NIRS) analysis of caffeine in roasted Arabica coffee by variable selection method of stability competitive adaptive reweighted sampling (SCARS). Spectrochim. Acta (A) Mol. Biomol. Spectrosc. 2013, 114, 350-356.

14. Fox, G.P.; Wu, A.; Yiran, L.; Force, L. Variation in caffeine concentration in single coffee beans. Food Chem. 2013, 61, 10772-10778.

15. Sereshti, H.; Samadi, S. A rapid and simple determination of caffeine in teas, coffees and eight beverages. Food Chem. 2014, 158, 8-13.

16. Oberleitner, L.; Grandke, J.; Mallwitz, F.; Reschgenger, U.; Garbe, L.A.; Schneider, R.J. Fluorescence polarization immunoassays for the quantification of caffeine in beverages. $J$. Agric. Food Chem. 2014, 62, 2337-2343.

17. McCusker, R.R.; Goldberger, B.A.; Cone, E.J. Caffeine content of specialty coffees. J. Anal. Toxicol. 2003, 27, 520-522.

18. McCusker, R.R.; Fuehrlein, B.; Goldberger, B.A.; Gold, M.S.; Cone, E.J. Caffeine content of decaffeinated coffee. J. Anal. Toxicol. 2006, 30, 611-613.

Bull. Chem. Soc. Ethiop. 2018, 32(1) 
19. Svorc, L.; Tomcik, P.; Svitkova, J.; Rievaj, M.; Bustin, D. Voltammetric determination of caffeine in beverage samples on bare boron-doped diamond electrode. Food Chem. 2012, $135,1198-1204$.

20. Del Campo, G.; Berregi, I.; Caracena, R.; Zuriarrain, J. Quantitative determination of caffeine, formic acid, trigonelline and 5-(hydroxymethyl) furfural in soluble coffees by ${ }^{1} \mathrm{H}$ NMR spectrometry. Talanta 2010, 81, 367-371.

21. Huck, C.W.; Guggenbichler, W.; Bonn, G.K. Analysis of caffeine, theobromine and theophylline in coffee by near infrared spectroscopy (NIRS) compared to high performance liquid chromatography (HPLC) coupled to mass spectrometry. Anal. Chim. Acta 2005, 538, 195-203.

22. Srdjenovic, B.; Djordjevic-Milic, V.; Grujic, N.; Injac, R.; Lepojevic, Z. Simultaneous HPLC determination of caffeine, theobromine, and theophylline in food, drinks, and herbal products. J. Chromatogr. Sci. 2008, 46, 144-149.

23. Wanyika, H.N.; Gatebe, E.G.; Gitu, L.M.; Ngumba, E.K.; Maritim, C.W. Determination of caffeine content of tea and instant coffee brands found in the Kenyan market. Afr. J. Food Sci. 2010, 4, 353-358.

24. Belay, A.; Kassahun, T.; Mesfin, R.; Araya, A. Measurement of caffeine in coffee beans with UV-Vis spectrometer. Food Chem. 2008,108, 310-315.

25. Demissie, E.G.; Woyessa, G.W.; Abebe, A. UV-Vis spectrometer determination of caffeine in green coffee beans, using Beer-Lambert's law and integrated absorption coefficient techniques. Scientific Study and Research-Chemistry and Chemical Engineering Biotechnology Food Industry 2016, 17, 109-123.

26. Weldegebreal, B.; Redi-Abshiro, M.; Chandravanshi, B.S. Development of new analytical methods for the determination of caffeine content in aqueous solution of green coffee beans. Chem. Cent. J. 2017, 11: 126. DOI: 10.1186/s13065-017-0356-3.

27. Farah, A.; Monteiro, M.C.M.; Calado, V.; Franca, A.S.; Trugo, L.C. Correlation between cup quality and chemical attributes of Brazilian coffee. Food Chem. 2006, 98, 373-380.

28. Phan, T.T.D. The influence of the coffee roasting process and coffee preparation on human physiology. PhD Thesis, Tomas Bata University, Zlín, Czech Republic, 2012. 